\title{
ANTERIOR IMPLANT RESTORATIONS - CHALLENGE AND COMPROMISE. A CASE REPORT
}

\section{Abstract}

Aim: to present implant restorative treatment and retreatment in light of patient feedback.

Summary: A patient with extensive restorative treatment including implant supported fixed prosthodontics is presented as not satisfied with the definitive restorations, which were ultimately rejected and removed. Communication with patient was affected by the fact that he could not use his native language during discussion with the dentists involved in the treatment. Moreover, the majority of dentists who participated in the treatment could not use their native languages.

After a number of unsuccessful provisional restorations, decision is made to start over the prosthetic design approach from wax-up stage.

Lately, precedence has been given to improved esthetics and lip support, while compromising on other desirable features, such as a smooth, easy to clean emergence profile. The patient was happy with the final outcome and agreed to spend extra time with hygiene measures, while benefiting from better esthetics and lip support.

Key learning points: 1. Patient expectations are paramount for treatment success and should be identified early on during evaluation phases.

2. Implant restorations are not without limitations and compromises may be necessary in order to provide an acceptable prosthesis.

3. Definitive restorations should only be fabricated and delivered after assurance that the design provided by provisionals was tried and accepted by the patient.

Keywords: implant, emergence profile, lip support

\section{Introduction}

After decades of implant dentistry with predictable results, titanium implants of various shapes and textures claim a mainstream role in providing infrastructure in state-of-the-art restorations.

Despite impressive standardization and ease of use of treatment protocols, anterior restorations supported by implants may still encounter problems. Sometimes, clinically satisfactory prostheses, as assessed by practitioners, are not accepted by certain patients.

\section{Case Presentation and History}

During the following, the reader is presented with a clinical case restored in the Department of Graduate Prosthodontics in the School of Dentistry - University of North Carolina (UNC) at Chapel Hill, U.S.A.

Mr. CM (male, 50 years old) presented with moderate generalized and localized severe periodontitis (Fig.1 a, b), seeking for treatment options. After a comprehensive

Received: 28 August 2014 Accepted: 13 September 2014

*Corresponding author:

Assistant Professor Sorin Uram-Tuculescu, DDS, MS, PhD

Department of Prosthodontics, School of Dentistry Virginia Commonwealth University Wood Memorial Building,

521 North 11th Street, Room\# 304 D

PO Box 980566 Richmond, VA23298-0566, USA Tel: 804-628-3742, Fax: 804-827-1017 e-mail: suramtucules@vcu.edu 

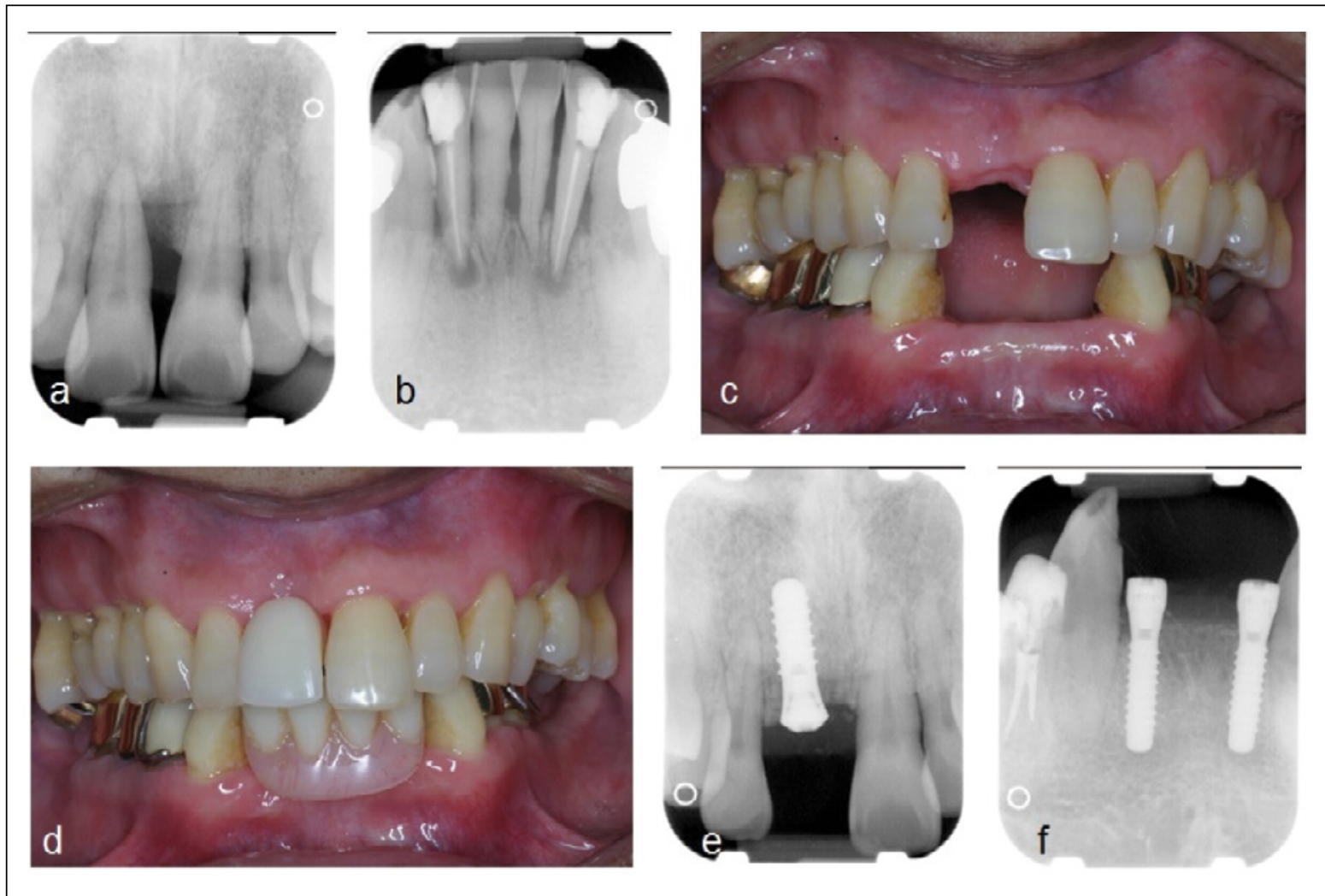

Figure 1. C.M. (male, 50):

a, b) radiographic appearance of localized severe periodontitis 11,42,41,31, 32, also apical periodontitis 42, 32;

c) clinical presentation after extraction of hopeless teeth and completing initial therapy;

d) upper and lower interim removable partial dentures for edentulous spaces 11, 42, 41, 31, 32;

e) radiographic appearance after implant placement 11;

f) radiographic appearance after implant placement 42,32

oral evaluation, photographs, and impressions for diagnostic casts, the patient was referred to the Department of Graduate Periodontics at the UNC School of Dentistry. Following extraction of hopeless teeth $(11,42,41,31,32)$ and completion of the initial therapy the patient returned to the Prosthodontics Department for restorative treatment options (Fig $1 \mathrm{c}$ ). Interim removable partial dentures were fabricated (Fig. 1 d) for the healing phase, while the patient was presented with several treatment options from removable prosthodontics to fixed partial dentures and implant supported restorations. The patient elected to have a number of posterior crowns with questionable prognosis being remade. As for the edentulous spaces, he decided to go for implant supported crowns/fixed prosthodontics.

The patient returned to the Department of Periodontics to have implants placed into the following positions: 11 Straumann tissue level Regular Neck (internal connection) - (Fig 1 e); 42 and 32 Straumann tissue level Narrow Neck (external hex connection) - (Fig $1 \mathrm{f}$ ).

After implants placement, abutments selection/ fabrication (Fig. 2 a, b), and impressions the patient abruptly asked to be reassigned to a different provider within the Department of Graduate
Prosthodontics. We received the lab work (Fig.2 $c, d)$ and saw the patient at delivery appointment, when he appeared satisfied with the outcome and after examining the restorations in the mirror consented to final cementation (Fig. 2 e). At that time we delivered a number of posterior porcelain fused to metal crowns (PFMs) along with implant supported PFM crown on 11 and implant supported fixed partial denture (FPD) from 32 to 42 .

In a matter of weeks the patient returned complaining about the shape of the lower FPD: "the bridge is off the tract", the way it is touching the tongue and the lower lip is not comfortable, there are "too big gaps between the bridge/crown and original teeth", "food scraps are collected in the spot", "I cannot talk with someone else at lunch or dinner", it does not look natural. It was immediately clear that the restoration was not accepted anymore, so we removed it and what followed was a series of provisional restorations as we tried different morphologies with more or less prominent cingulums, various curvatures, and different bucco-lingual thicknesses, but after another couple of months in the business, there was still no acceptance of our designs. During this time, Mr. CM provided us with several drawings of 

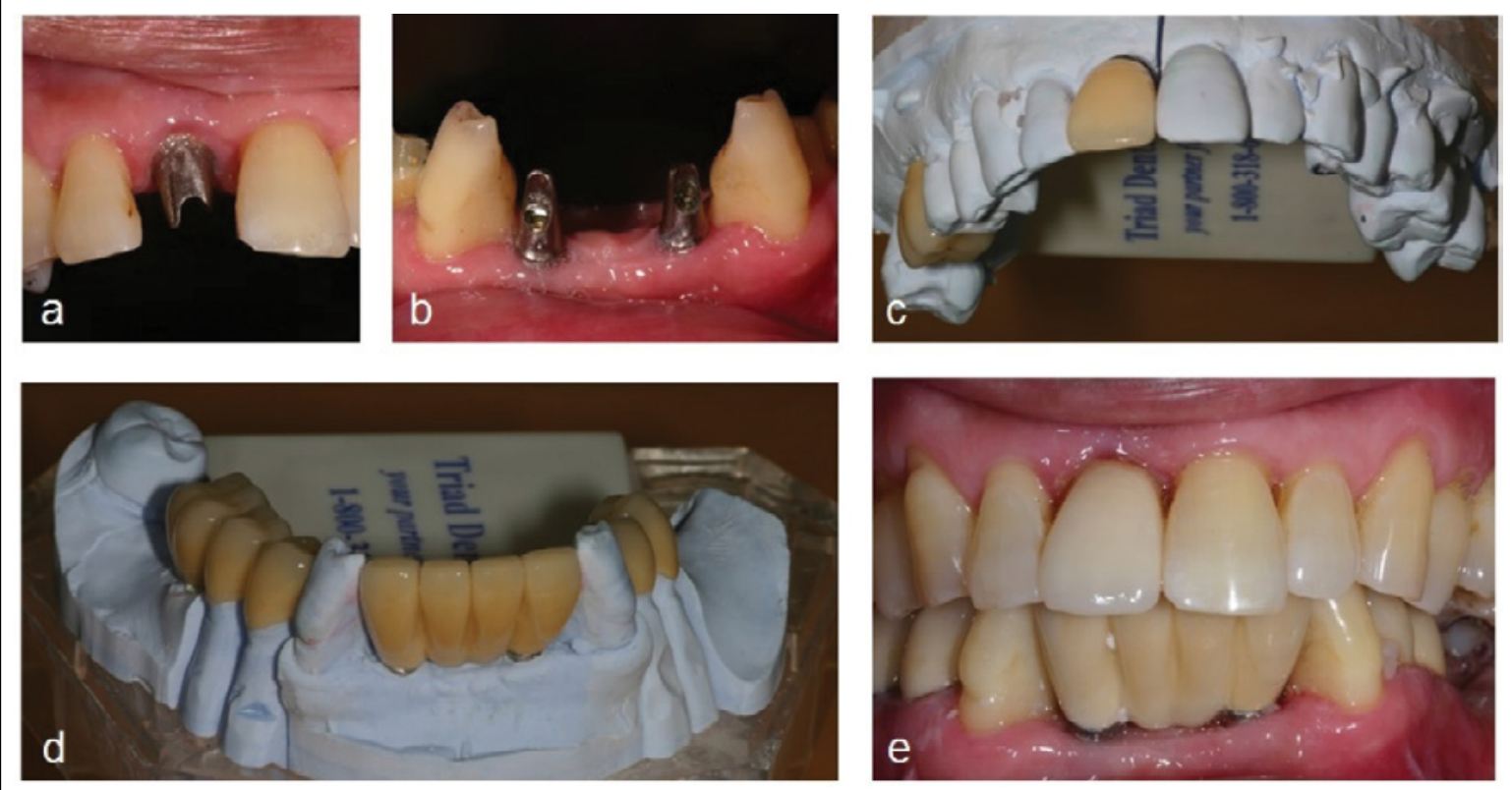

Figure 2. $\mathrm{CM}$ (male, 50):

a) 1.1. custom abutment;

b) 42 \& 32 angled abutments;

c, d) finished lab work on master casts;

e) clinical aspect of anterior restorations at delivery
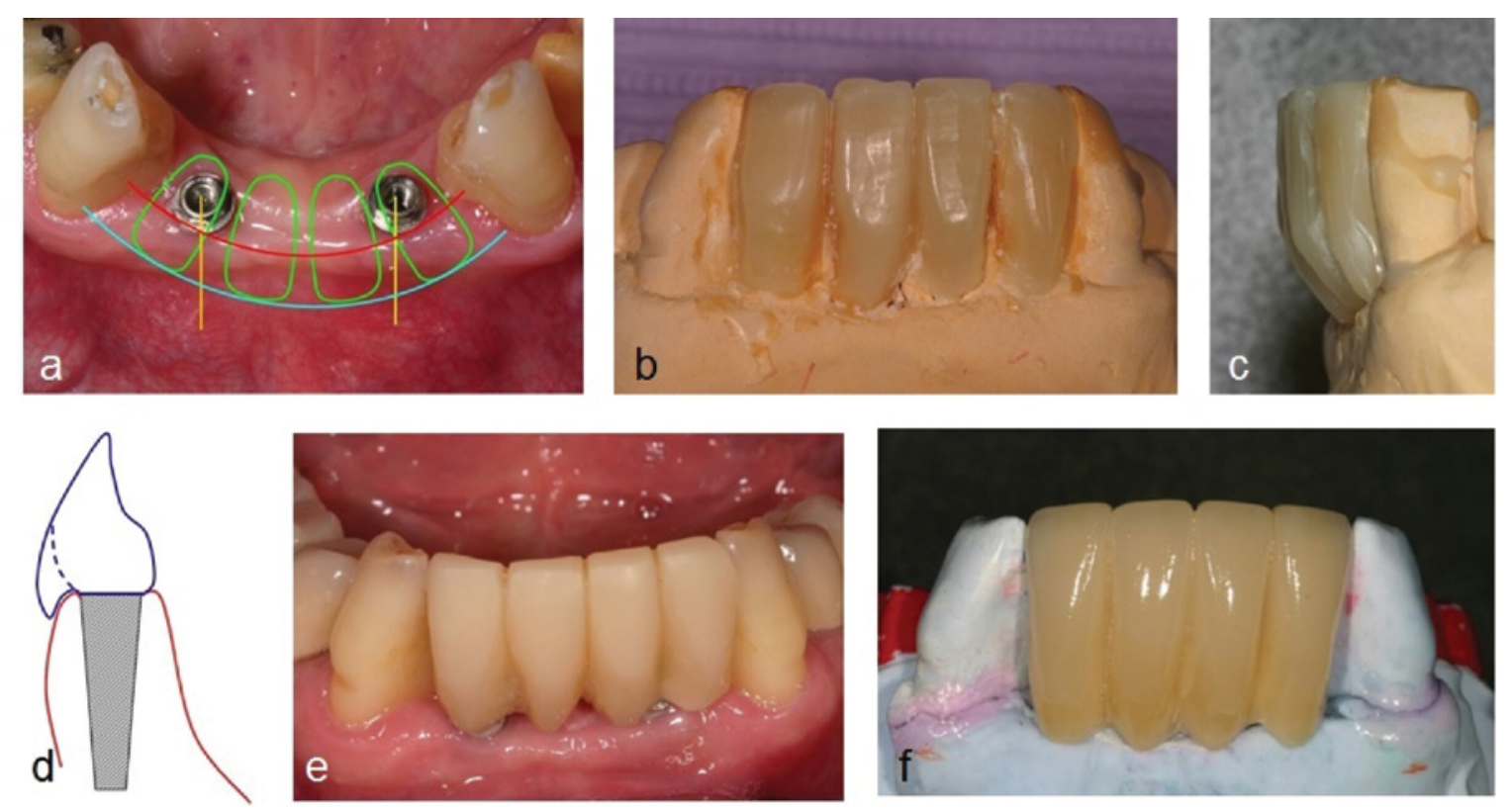

Figure 3. $\mathrm{CM}$ (male, 50):

a) implant platforms positioning in respect to expected arch anatomy - predicted outlines of lower incisors (green); curvature of buccal aspects of lower incisors to conform to arch anatomy (blue); curvature of initial restorative platform at implant level (red); projections of implant platforms in the embrasures (yellow);

b, c) wax-up 32 to 42 following anatomic principles only;

d) proposed emergence profile design of implant/abutment supported retainer in "modified ridge lap" to provide esthetics and lip support;

e) last provisional fabricated according the final wax-up;

f) final restoration on master cast.

what he believed the problem would be. Mr. CM first language is not English, my first language is not English and our first language is not the same, so we could expect some difficulty in communication. Therfore, at some point Mr. CM brought a dental technician friend of his (who could also speak Mr. 

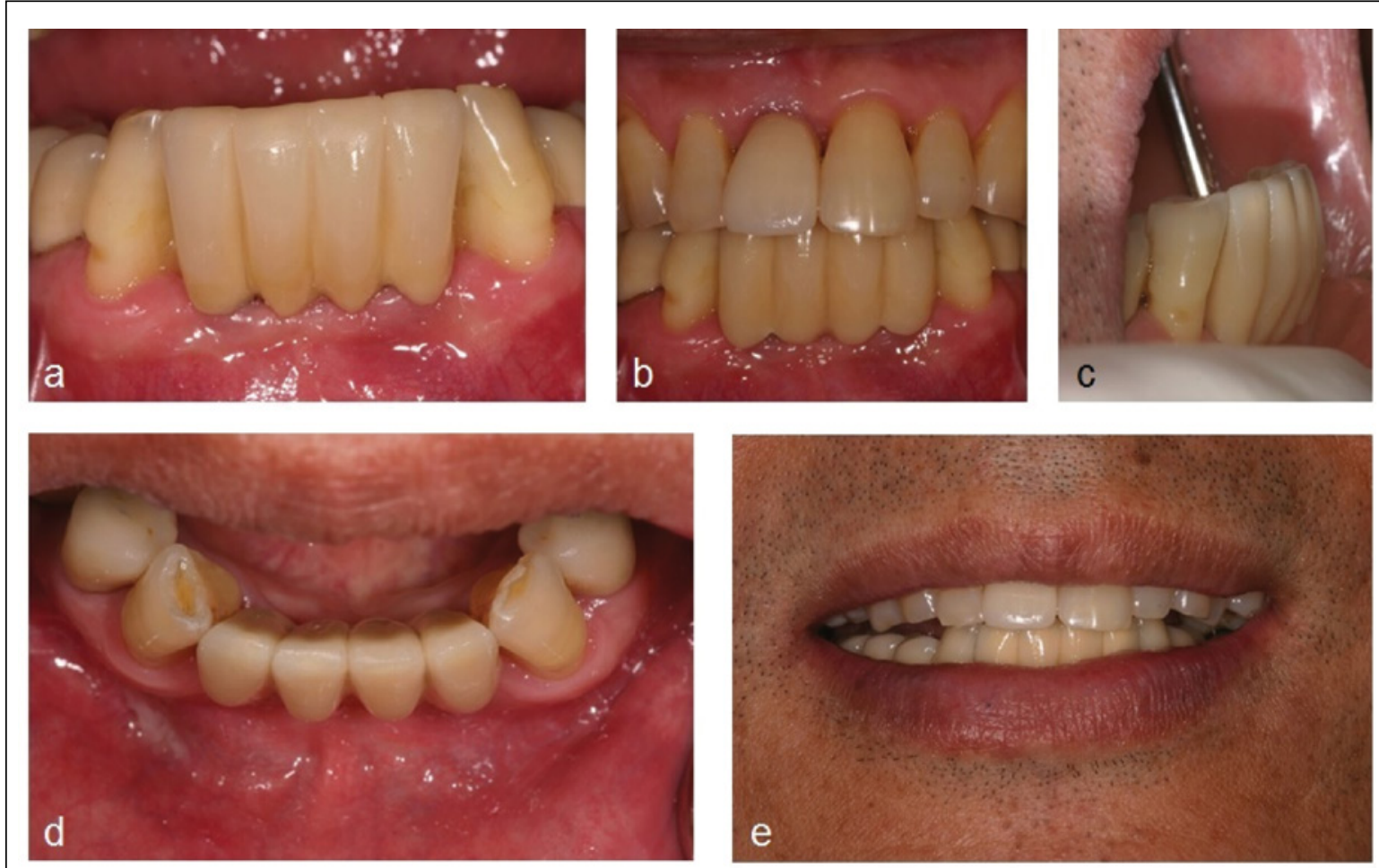

Figure 4. Clinical appearance of final restoration 42 to 32 with "modified ridge lap" design from implant platforms to achieve lip support and esthetics:

a) buccal view; b) buccal view - maximum intercuspation; c) lateral view;

d) occlusal view; e) patient reports adequate lip support and "feel"

CMs native language) to further explain the issues, but again, it was not clear to us what was really the blueprint Mr. CM wanted us to use for his FPD.

After a considerable lab and clinical lapse of time we made the decision to disregard the last months of treatment, and just go back to the drawing board and start over from the moment after the implant placement. As we analyzed the implant positioning with respect to the assumed positions of lower incisors, we realized that the implant platforms were situated more lingually than desired, and if we kept holding the idea that the best emergence profile (1) for efficient cleaning (widely open embrasures) is to be employed, then the implant platforms (especially 32) would appear rather in the embrasures than corresponding to the implant abutments (Fig. 3 a).

We also considered some of the complaints of Mr. $\mathrm{CM}$ - too big spaces between teeth, uncomfortable tactile sensation on the lower lip - and with that in mind, we made a new wax-up, following anatomic principles only (Fig. 3 b, c).

Then we fabricated a provisional according to the new wax-up, understanding that a "modified ridge lap" design was inevitable not only in the area 31 and 32 , but also in front of the implant platforms 32, 42 (Fig.3 d).

Our last provisional restoration (Fig.3 e) was a success, we earned the patient's acceptance and requested the laboratory to fabricate the definitive PFM implant supported FPD with a similar shape. It took a couple of attempts for the laboratory to generate a definitive prosthesis close enough to our provisional design, but once that was achieved we had a happier patient (Fig.4).

Mr. CM reported that the feel on the lip is right and the look is great, but noticed the difficulties in cleaning around the implants. Mr. CM was explained that considering the position of the implants, transitioning from the round shapes of the implant platforms to the flattened shapes of lower incisors without large embrasures and without sacrificing the anatomy was not physically possible. He accepted the outcome as the best compromise and agreed to spend the extra-time with the floss around his fingers.

After a few weeks we heard again from Mr. CM stating that the shape of the crown 11 is not right (Fig 5 a).

Intraoral adjustments and polishing did not bring any success, so the existing crown was removed and a new provisional was made trying to better mimic the anatomy of the incisal third of 21 while providing a smooth emergence profile from the implant platform (Fig. 5 b). At that time we also learned that the 11 implant platform was situated more lingually and more mesially as compared to expected emergence if symmetry with the tooth 21 is to be considered. 

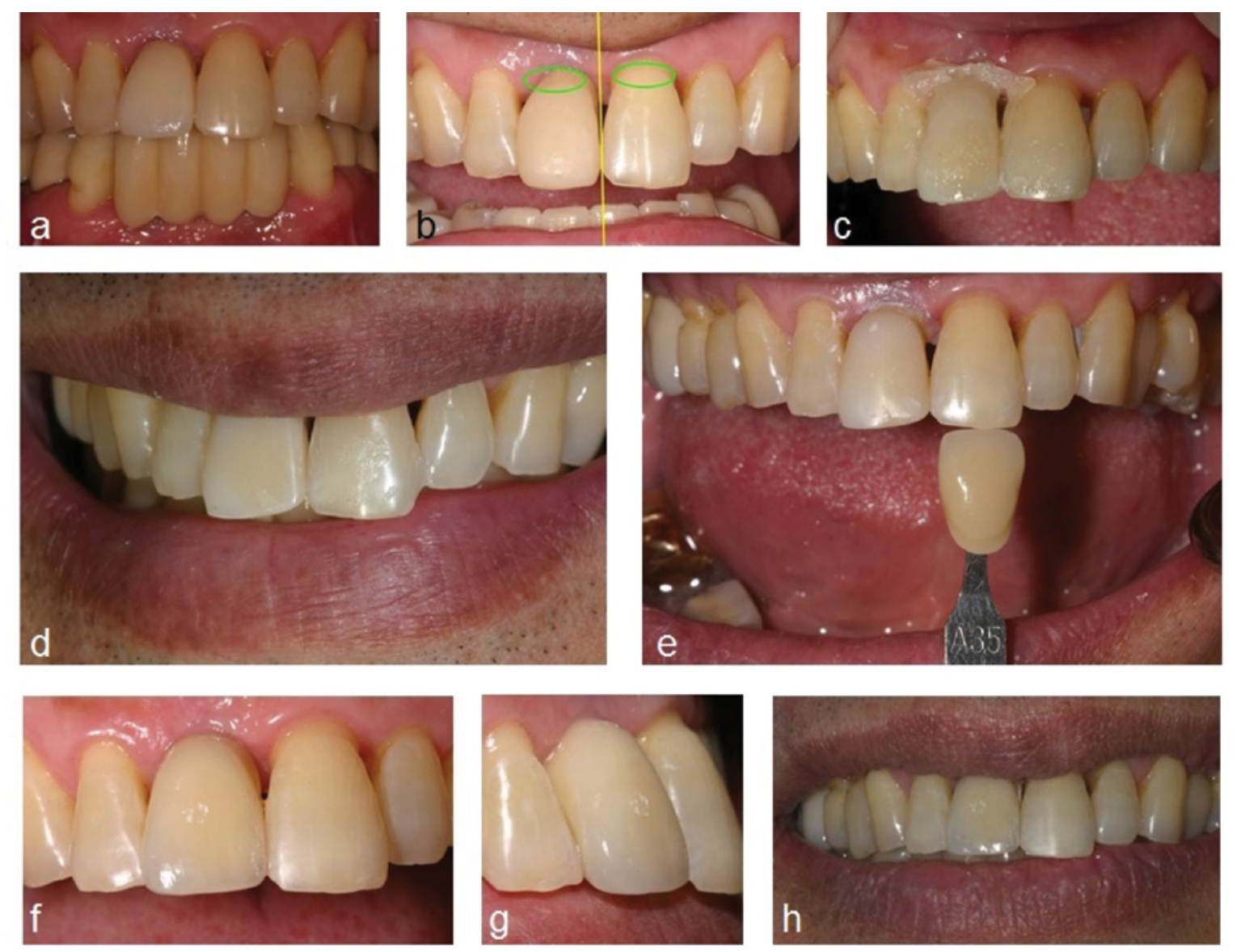

Figure 5. CM (male, 50):

a) 11. implant/abutment supported PFM crown is not accepted anymore;

b) new provisional restoration trying to better mimic the anatomy of 12; midline and expected positioning of cervical outline were also evaluated;

c) fabrication of a second provisional compromising between symmetry of 11 and 21, emergence profile and implant platform positioning - accepted by patient;

e) new shade determination;

$\mathrm{f}, \mathrm{g}$ ) final PFM restoration 11;

h) patient confirms adequate anatomy and shade match

Our crown looked crooked, with an angle from the cervical third to the incisal third and was discarded. The next provisional attempt, a different compromise, with slightly wider cervical aspects, less bulbous distal profile and improved symmetry at the incisal edge level (Fig 5 c, d) was accepted by the patient. A new shade determination was made (Fig 5 e), then the best PFM representation of our provisional was delivered to earn a happy patient again (Fig. $5 f, g, h)$.

\section{Discussion}

From the perspective of the events we could reiterate that the implant positioning in the esthetic zone is of critical importance, especially for tissue level implants, which, at the time of this treatment were not uncommon.
Promoting by default the most hygienically favorable design may overlook other aspects which could be regarded at least as important by our patients. In our case a proper lip support in the cervical area, along with better esthetics were certainly more appreciated that an "easy to clean restoration".

Engineering the best emergence profile (case dependent) within the limitations of available bone, implant positioning and design constitutes a fine compromise which may need multiple trial \& error stages before reaching an acceptable form. Careful design, fabrication, evaluation, refinement of provisional restorations represents the safest path in order to obtain the best achievable anatomy before ordering a final restoration in the lab.

Nowadays, widespread use of bone level implants, immediate placement and 
provisionalization can offer better conditions to improve soft tissue anatomy around implants with predictable aesthetic results $(2-5)$. It is worth remembering that patientreported measures may be more sensitive than objective measures for detecting differences between prosthetic treatments (6-9). The discrepancy between the patient's perceptions and the outcomes of functional tests suggests that study subjects' and scientists' concepts of function differ, or that subjective and objective data assess very different aspects of oral behavior.

\section{Acknowledgements}

The author acknowledges the support provided by the Department of Graduate Prosthodontics of the School of Dentistry - University of North Carolina at Chapel Hill (Program Director - Dr. Lyndon Cooper) for the completion of this treatment.

The author's gratitude is also extended to Dr. Marlene Teo (Department of Graduate Periodontics), who was responsible for the surgical phases, Dr. Hitomi Akimoto, who started the restorative phase, and Dr. Dina Dedi, who closely supervised the entire restorative phase.

\section{Conflict of interest statement}

There are no known conflicts of interest associated with this publication and there has been no significant financial support for this work that could have influenced its outcom.

\section{Bibliography}

1. Stein RS, Kuwata M. A dentist and a dental technologist analyze current ceramo-metal procedures. Dent Clin North Am 1977;21(4):729-749.

2. Petrungaro PS. Creation and preservation of natural soft tissue emergence profiles around dental implants in the esthetic zone. J Cosmetic Dent 2009;24(4):66-80.

3. Rodriguez AM, Rosenstiel SF. Esthetic considerations related to bone and soft tissue maintenance and development around dental implants: report of the Committee on Research in Fixed Prosthodontics of the American Academy of Fixed Prosthodontics. J Prosthet Dent 2012;108(4):259-267.

4. Wittneben JG, Buser D, Belser UC, Brägger U. Peri-implant soft tissue conditioning with provisional restorations in the esthetic zone: the dynamic compression technique. Int J Periodontics Restorative Dent 2013;33(4):447-455.

5. Dos Santos Nunes Reis JM, de Oliveira Abi-Rached F, Scardueli CR, Pinelli LA. Modified indexing technique for the immediate interim restoration of a dental implant. J Prosthet Dent 2014;112(2):369-372.

6. de Grandmont $P$, Feine JS, Taché $R$, Boudrias $P$, Donohue WB, Tanguay R, Lund JP. Within subject comparisons of implant-supported mandibular prostheses: psychometric evaluation. J Dent Res 1994;73(5):1096-1104.

7. Feine JS, de Grandmont P, Boudrias P, Brien N, LaMarche C, Taché R, Lund JP. Within-subject comparisons of implantsupported mandibular prostheses: choice of prosthesis. J Dent Res 1994;73(5):1105-1111.

8. Feine JS, Maskawi K, de Grandmont P, Donohue WB, Tanguay $R$, Lund JP. Within-subject comparisons of implant-supported mandibular prostheses: evaluation of masticatory function. J Dent Res 1994;73(10):1646-1656. 9. Garrett NR, Kapur KK, Perez P. Effects of improvements of poorly fitting dentures and new dentures on patient satisfaction. J Prosthet Dent 1996;76(4):403-413. 